\title{
Association of Regional Bioelectrical Phase Angle with Physical Performance: a Pilot Study in Elite Rowers
}

\author{
F. Campa ${ }^{1}$, G. Mascherini ${ }^{2 *}$, G. Polara ${ }^{2}$, D. Chiodo ${ }^{2}$, L. Stefani ${ }^{2 *}$ \\ 1 Department for Life Quality Studies, University of Bologna, Rimini, Italy \\ 2 Department of Experimental and Clinical Medicine, University of Florence, Florence, Italy \\ * These authors contributed equally to this work
}

\section{CORRESPONDING AUTHOR:}

Gabriele Mascherini

Department of Experimental and Clinical

Medicine

University of Florence

largo Brambilla 3

50134 Florence, Italy

E-mail: gabriele.mascherini@unifi.it

DOI:

10.32098/mltj.03.2021.09

LEVEL OF EVIDENCE: 2B

\begin{abstract}
SUMMARY
Background. This study aimed to examine the association between regional Phase Angle $(\mathrm{PhA})$ and physical performance in athletes where the use of specific body segments is required.

Methods. Sixteen elite-level rowers ( 13 male aged $17.6 \pm 2.1 \mathrm{yr} ; 3$ female aged $21.0 \pm 4.4 \mathrm{yr}$ ) participated in this investigation. Raw bioimpedance parameters were obtained with a phase-sensitive $50 \mathrm{kHz}$ bioelectrical impedance analysis (BIA) device and fat-free mass, percentage of fat mass (FM\%), and arms and legs lean soft tissue (ALST and LLST, respectively) were estimated using specific BIA-equation developed for athletes. The time (2000t) and the mean power (MP) expressed during the $2000 \mathrm{~m}$ test performed on a rowing ergometer were measured.

Results. The major findings of the study were that upper hemisome $\mathrm{PhA}(\mathrm{UPhA})$ were more strongly related with $2000 \mathrm{t}(\mathrm{R} 2=0.35, \mathrm{p}=0.015)$ and $\mathrm{MP}(\mathrm{R} 2=0.40, \mathrm{p}=0.009)$ than whole-body $\mathrm{PhA}$. Additionally, not only UPhA maintained a significant relationship with 2000t ( $p=0.001)$ and MP ( $p=0.001)$, even after adjustment for the co-variables sex, ALST, and FM\%, but the explained variance increased to R2 $=0.72$ and R2 $=0.78$, respectively.

Conclusions. These results suggest that the regional $\mathrm{PhA}$ might be used as a tool for evaluating performance related parameters in sports where specific body segments are involved, preferring it to the whole-body measured value.
\end{abstract}

\section{KEY WORDS}

Athletes; bioimpedance; BIVA; body composition; rowing.

\section{BACKGROUND}

The assessment of body composition through economic and easy-to-use techniques allows the physician and strength trainer to monitor the athlete's condition in order to achieve an optimal health status and therefore a higher level of performance. Several variables in body composition are known to be related to strength and movement patterns (1-3). In particular, an increase in lean mass contributes to the development of strength and power while a reduction in non-essential body fat contributes to the development of muscular and cardiorespiratory endurance, speed and agility $(4,5)$.

Nowadays, Bioelectrical Impedance Analysis (BIA) represents one of the most used methods to assess body composition in sport (6). Although BIA measures the opposition of body tissues to the flow of an alternating current, its measurement modality and the assessments that can therefore be obtained vary among the different devices (7). The study of bioelectrical properties in athletes made it possible to create specific references (8-11) useful for monitoring body composition during the competitive season and during the follow-up after an injury (12-14). Among the raw bioimpedance parameters, the phase angle $(\mathrm{PhA})$ has been proposed as an indicator of cellular health, cell membrane integrity $(7,15)$ and representative of the intracellular/extracellular water (ICW/ECW) ratio (16-18). While the usefulness of $\mathrm{PhA}$ in the clinical setting is widely recognized, 
scientific research has recently begun to show its interest in exploring the associations between $\mathrm{PhA}$, health status, and sport performance. In healthy athletes, the $\mathrm{PhA}$ shows higher values compared to the phases of the competitive season characterized by high training load or acute and chronic fatigue (13, 19, 20). Recently, Nabuco et al. (20) reported the relationship between whole-body $\mathrm{PhA}(\mathrm{WBPhA})$ and sprint performance, also highlighting how it is inversely correlated with perceived fatigue in soccer players.

Compared to conventional whole-body BIA, regional analysis allows measuring the composition of different body segments, overcoming the theoretical limits underlying conventional analysis such as considering the human body as the set of five cylinders of uniform resistivity (21). Recent studies suggest that regional BIA at the lower limb level provides important information in soccer and cycling populations. These information refers to the difference between the sexes, in which male athletes have higher lower limb PhA values than female athletes (22); the changes in body fluids which can occur after a muscle injury, in which a decreases in regional $\mathrm{PhA}$ were observed where there is cellular damage with consequent accumulation of fluids in the extracellular compartment (14); and the change in cell number and/ or size following a training program shown by an increase in lower limb PhA (19). A study on cyclists participating in the 2012 Giro d'Italia showed that while WBPhA did not change, lower hemisome $\mathrm{PhA}$ ( $\mathrm{LPhA}$ ) decreased during a three-week stage race (23).

However, the use of regional $\mathrm{PhA}$ as an indicator of the performance of athletes from other sports that predominantly involve other body segments has yet to be determined.

Therefore, the aim of this study was to verify through a pilot study design the association between regional $\mathrm{PhA}$ with physical performance in rowers, in which the use of the upper body is particularly required. Our hypothesis was that regional $\mathrm{PhA}$ could be more informative than that measured through a whole-body BIA approach.

\section{MATERIALS AND METHODS}

\section{Participants}

A group of 16 elite rowers from the same sports club voluntarily participated in the study. This group consisted of 13 males $(17.6 \pm 2.1 \mathrm{yrs})$ and 3 females $(21.0 \pm 4.4 \mathrm{yrs})$ who train following the guidelines of the Italian Rowing Federation which indicate daily sessions with the possibility of two training sessions per day, corresponding to a training volume of the last 6 months from 15 to 25 hours per week. The study was performed during the in-season phase of the competitive season; therefore, the athletes were at the high- est level of training. Athletes had at least 3-year competitive rowing experience at the national level. Inclusion criteria for the subjects included being Caucasian, practicing rowing at national level for at least 5 years and having obtained sports eligibility. Exclusion criteria were not providing informed consent, having injuries that compromise the bioimpedance assessment or participation in performance tests and not having obtained sports eligibility.

Written informed consent from parents or guardians was retrieved for rowers under the age of 18 . After receiving consent, all subjects underwent a voluntary assessment of body composition and performance assessments. The study was carried out in conformity with the ethical standards laid down in the 1975 declaration of Helsinki, in addition the study meets the ethical standards of the journal (24). This study is part of a project of the Tuscany Region called "Sports Medicine to support regional surveillance systems"; the Regional Prevention Plan 2014-2018 with the code O-Range18, approved it.

\section{Bioimpedance and body composition analysis}

The raw bioimpedance parameters $[(\mathrm{PhA}$, resistance $(\mathrm{R})$ and reactance $\left(\mathrm{Xc}_{\mathrm{c}}\right)$ ] were obtained using a phase-sensitive segmental bioelectrical analyzer (BIA 101 BIVA PRO, Akern, Florence, Italy) with a current of $250 \mu \mathrm{A}$ at a single frequency of $50 \mathrm{kHz}$. After cleaning the skin with isotropy alcohol, four low intrinsic impedance adhesive electrodes (Biatrodes Akern Srl, Florence, Italy) were placed on the hands back and other four electrodes on the neck of the corresponding feet, respecting the standard protocol (25). R, Xc, and PhA were measured directly and automatically for each body segment, and the values were given in $\mathrm{ohm}$. The device was calibrated using the standard control circuit supplied by the manufacturer that has a known impedance ( $\mathrm{Rz}^{1 / 4} 380 \mathrm{Ohm} 1 \%$ precision, and Xc $1 / 447$ Ohm $1 \%$ precision). The test-retest CV in 16 participants for $\mathrm{R}, \mathrm{Xc}$, and $\mathrm{PhA}$ was $0.3 \%, 0.8 \%$, and $0.9 \%$ respectively. BIA was performed with patients lying supine with their limbs (figure 1) placed slightly away from their body, after an overnight fast, and having emptied their bladders. BIA measurements were all taken by the same-trained investigator to avoid inter-observer errors. Arms and legs lean soft tissue (ALST and LLST, respectively), fat-free mass (FFM), fat mass (FM), and percentage of fat mass (FM\%) were estimated using a specific equation developed for athletes (26, 27) designed and validated with the same BIA model:

1. FFM $(\mathrm{kg})=-2.261+0.327-\mathrm{S}^{2} / \mathrm{R}+0.525 \times \mathrm{Wt}+$ $5.462 \times$ Sex.

Where:

- sex is 0 if female or 1 if male; 
- Wt is weight in $\mathrm{kg}$;

- $\mathrm{S}$ is stature in $\mathrm{cm}$;

- $\mathrm{R}$ is resistance;

- $\mathrm{R}^{2}=0.94 ; \mathrm{SEE}=3.0 \mathrm{~kg}$;

2. $\mathrm{FM}(\mathrm{Kg})=$ Body weight - FFM.

3. Arms LST $(\mathrm{kg})=0.940 \times \mathrm{Sex}+0.042 \times \mathrm{Wt}+0.080 \times$ $\mathrm{S}^{2} / \mathrm{R}+0.024 \times \mathrm{Xc}-3.927$.

Where:

- sex is 1 if female or 0 if male;

- Wt is weight in $\mathrm{kg}$;

- $\mathrm{S}$ is stature in $\mathrm{cm}$;

- $\mathrm{R}$ is resistance;

- $\mathrm{Xc}$ is reactance; $\mathrm{R}^{2}=0.89 ; \mathrm{SEE}=0.62 \mathrm{~kg}$.

4. Legs LST $(\mathrm{kg})=1.983 \times \mathrm{Sex}+0.154 \times \mathrm{Wt}+0.127 \times$ $\mathrm{S}^{2} / \mathrm{R}-1.147$.

Where:

- sex is 1 if female or 0 if male;

- Wt is weight in $\mathrm{kg}$;

- $\mathrm{S}$ is stature in $\mathrm{cm}$;

- $\mathrm{R}$ is resistance;

- and $\mathrm{Xc}_{\mathrm{c}}$ is reactance; $\mathrm{R}^{2}=0.81, \mathrm{SEE}=1.95 \mathrm{~kg}$.

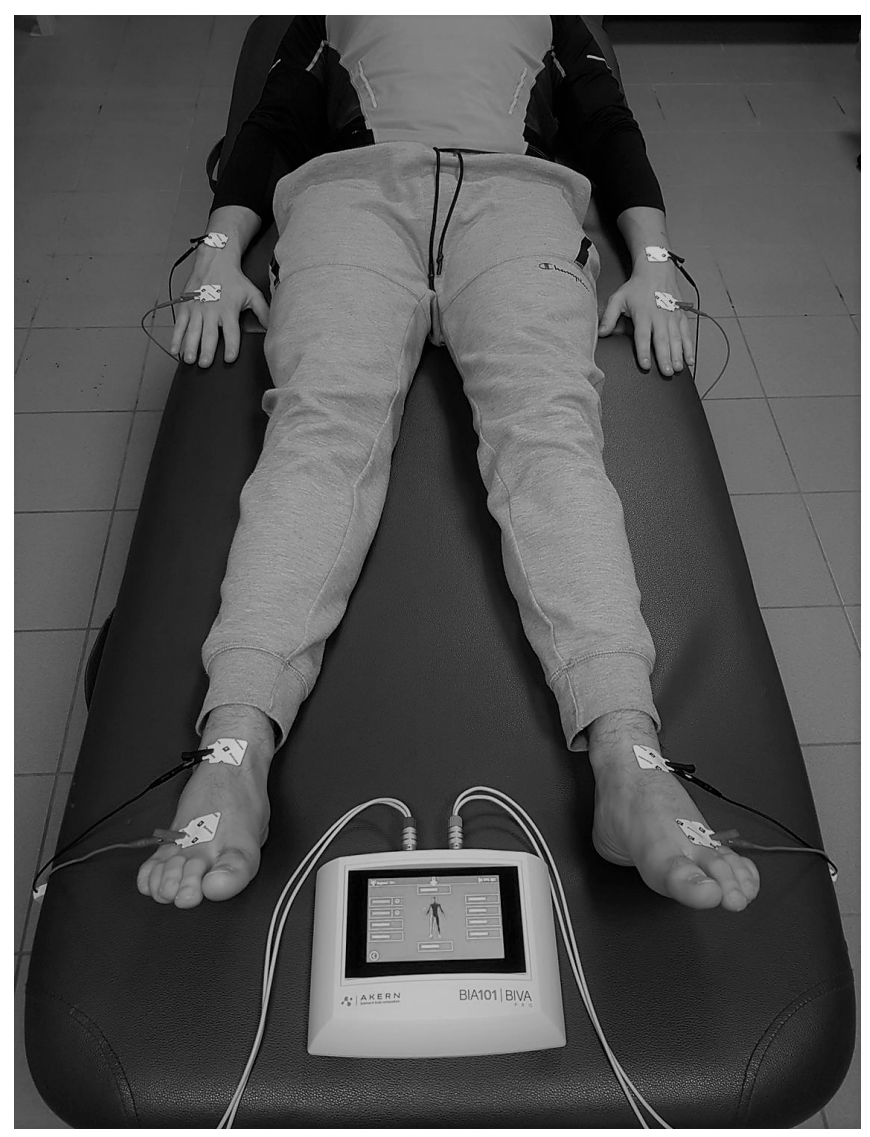

Figure 1. Procedures for regional bioimpedance analysis.

\section{Physical performance assessment}

After the body composition assessment, the rowers performed an all-out $2000 \mathrm{~m}$ row on a rowing machine (Concept2, Mod. D, Morisville, USA) designed to simulate a real race on water (28). From this test the total time it took to complete the distance (2000t) and the mean power (MP) were recorded. The MP was evaluated with a computer integrated (Concept PM3) to the ergometer, which measured the power of each stroke in Watts, providing at the end of the test the mean value of the strokes performed during the $2000 \mathrm{~m}$ of rowing.

\section{Statistical analysis}

All data are expressed as mean as standard deviation. To verify the normality of the data, the Shapiro-Wilk test was applied. The mean standard deviation was calculated for each variable. A preliminary bivariate correlation analysis was used to assess the association between bioelectric, body composition, and physical performance parameters. Multiple regression analysis was performed to test whether segmental phase angle (independent variable) is related with 2000t and MP (dependent variables) after adjusting for potential covariates, such as sex, ALST, and FM\%. Statistical significance was predetermined as $\mathrm{p}<0.05$. Data were analyzed with IBM SPSS Statistics, version 24.0 (IBM Corp., Armonk, NY, USA).

\section{RESULTS}

Anthropometric parameters, whole body and regional BIA analysis and rowing test performance are shown in table I.

Figure 2 shows the individual bioimpedance vectors plotted on the tolerance ellipses of the male and female athletes' population (9). Seven male rowers fell into the $50^{\text {th }}$ percentile, while 5 within the $75^{\text {th }}$. All three female rowers were included into the $50 \%$ tolerance ellipse.

The matrix of correlations between bioelectrical, body composition, and physical performance variables is shown in table II. Whole body and upper limb phase angle (UPhA) were both significantly associated $(\mathrm{p}<0.05)$ with physical performance measures, whereas no correlation between LPhA and time in rowing $2000 \mathrm{~m}$ as well as MP were found. Time in rowing $2000 \mathrm{~m}$ and MP showed a significant association with ALST, LLST, and FM\% measures. The correlations between WPHA and UPhA with 2000t and MP are shown in figure 3; in both analyzes, UPhA showed a stronger correlation with physical performance parameters than WBPhA. 

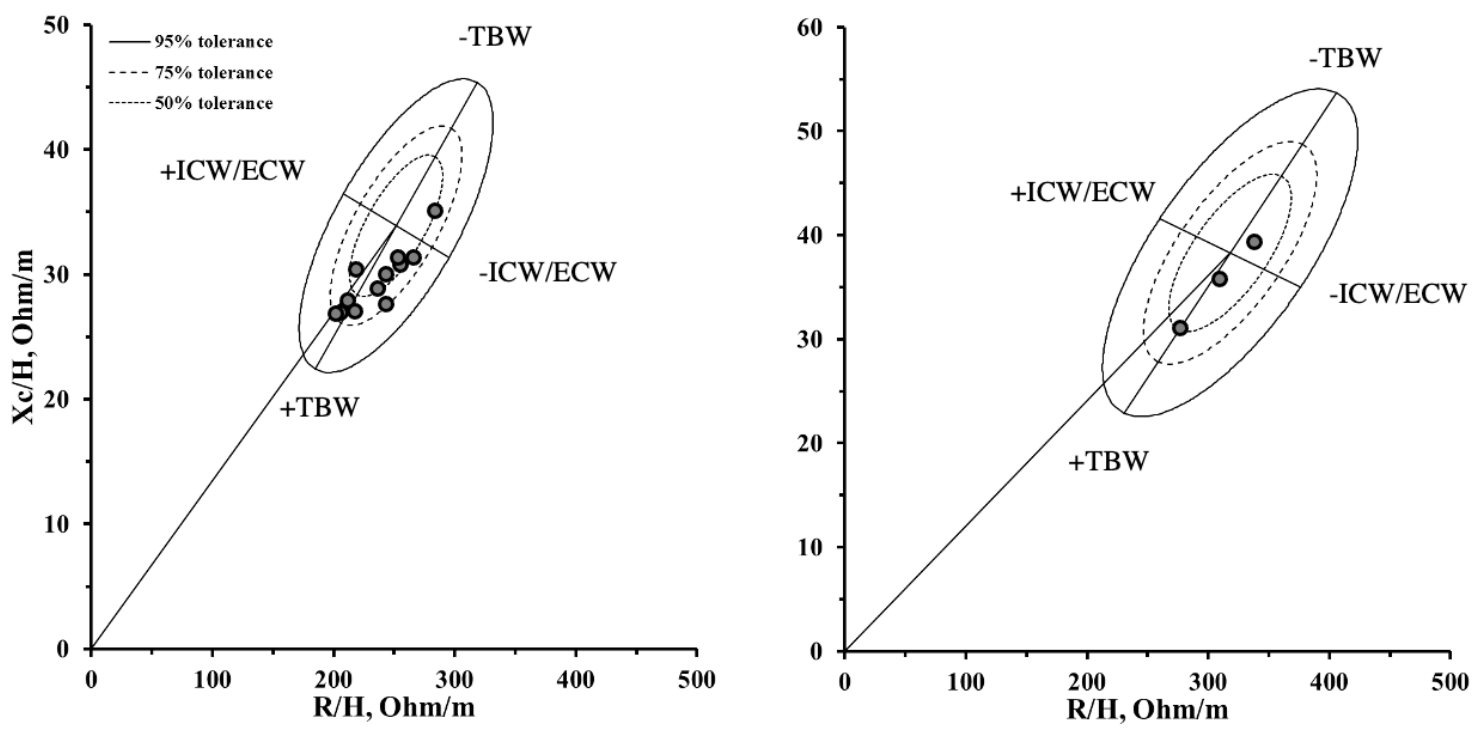

Figure 2. Individual bioimpedance vectors of the rowers (male on the left and female on the right) plotted on the tolerance ellipses of the athletes' population (9).

Table I. Anthropometric parameters, whole body and regional BIA analysis and rowing test performance.

\begin{tabular}{lcc}
\hline & Male $(\mathbf{n}=\mathbf{1 3})$ & Female $(\mathbf{n}=\mathbf{3})$ \\
\hline Age $($ years $)$ & Mean \pm SD & Mean \pm D \\
\hline Height $(\mathrm{cm})$ & $17.6 \pm 2.1$ & $21.0 \pm 4.4$ \\
\hline Weight $(\mathrm{kg})$ & $1.84 \pm 0.1$ & $1.7 \pm 0.1$ \\
\hline Body mass index $\left(\mathrm{kg} / \mathrm{m}^{2}\right)$ & $75.4 \pm 9.1$ & $63.5 \pm 7.1$ \\
\hline $\mathrm{R}(\mathrm{ohm})$ & $22.8 \pm 1.9$ & $23.1 \pm 2.2$ \\
\hline Xc $(\mathrm{ohm})$ & $410.0 \pm 37.1$ & $522.3 \pm 75.3$ \\
\hline WBPhA $\left(^{\circ}\right)$ & $52.6 \pm 4.8$ & $56.2 \pm 4.9$ \\
\hline Upper hemisome $\mathrm{R}(\mathrm{ohm})$ & $6.5 \pm 0.4$ & $6.1 \pm 0.4$ \\
\hline Upper hemisome Xc $(\mathrm{ohm})$ & $454.9 \pm 44.9$ & $517.1 \pm 72.4$ \\
\hline UPhA $\left(^{\circ}\right)$ & $48.3 \pm 3.8$ & $49.4 \pm 4.4$ \\
\hline Lower hemisome $\mathrm{R}(\mathrm{ohm})$ & $6.1 \pm 0.5$ & $5.5 \pm 0.3$ \\
\hline Lower hemisome Xc $(\mathrm{ohm})$ & $441.0 \pm 46.5$ & $478.4 \pm 79.1$ \\
\hline LPhA $\left(^{\circ}\right)$ & $52.0 \pm 5.8$ & $55.4 \pm 2.2$ \\
\hline FFM $(\mathrm{kg})$ & $6.7 \pm 0.5$ & $6.9 \pm 0.8$ \\
\hline FM $(\%)$ & $66.3 \pm 6.9$ & $48.6 \pm 5.4$ \\
\hline ALST $(\mathrm{kg})$ & $11.8 \pm 2.9$ & $23.4 \pm 5.6$ \\
\hline LLST $(\mathrm{kg})$ & $6.3 \pm 0.9$ & $5.3 \pm 0.8$ \\
\hline 2000 t $(\mathrm{sec})$ & $19.6 \pm 2.2$ & $17.4 \pm 1.8$ \\
\hline MP $($ watt $)$ & $407.3 \pm 17.3$ & $464.3 \pm 1.2$ \\
\hline R & $334.5 \pm 44.2$ & $222.9 \pm 1.7$
\end{tabular}

R: resistance; Xc: reactance; WBPhA: whole body phase angle; UPhA: upper hemisome phase angle; LPhA: lower hemisome phase angle; FFM: fat free mass; FM: fat mass; ALST: arms lean soft issue; LLST: leg lean soft tissue; MP: mean power. 
Table II. Matrix of correlations between bioimpedance, body composition, and performance parameters.

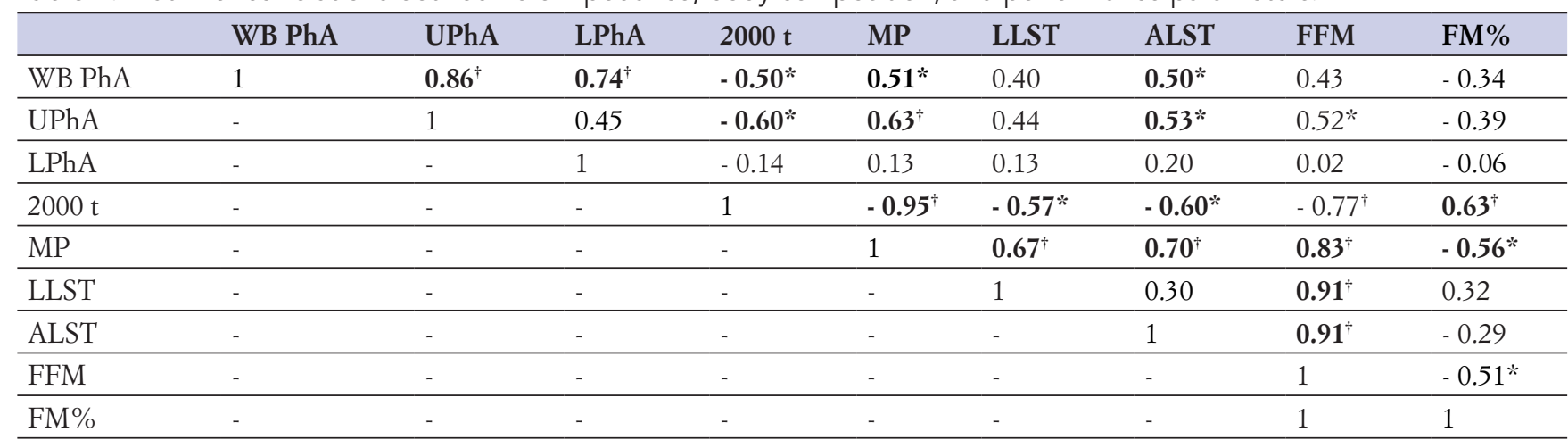

$*: \mathrm{P}<0.05 ;{ }^{\ddagger}: \mathrm{P}<0.005$. WB PhA: whole body phase angle; UPhA: upper hemisome phase angle; LPhA: lower hemisome phase angle; MP: mean power; LLST: legs lean soft tissue; ALST: arms lean soft tissue; FFM: fat-free mass; FM\%: percentage of fat mass.

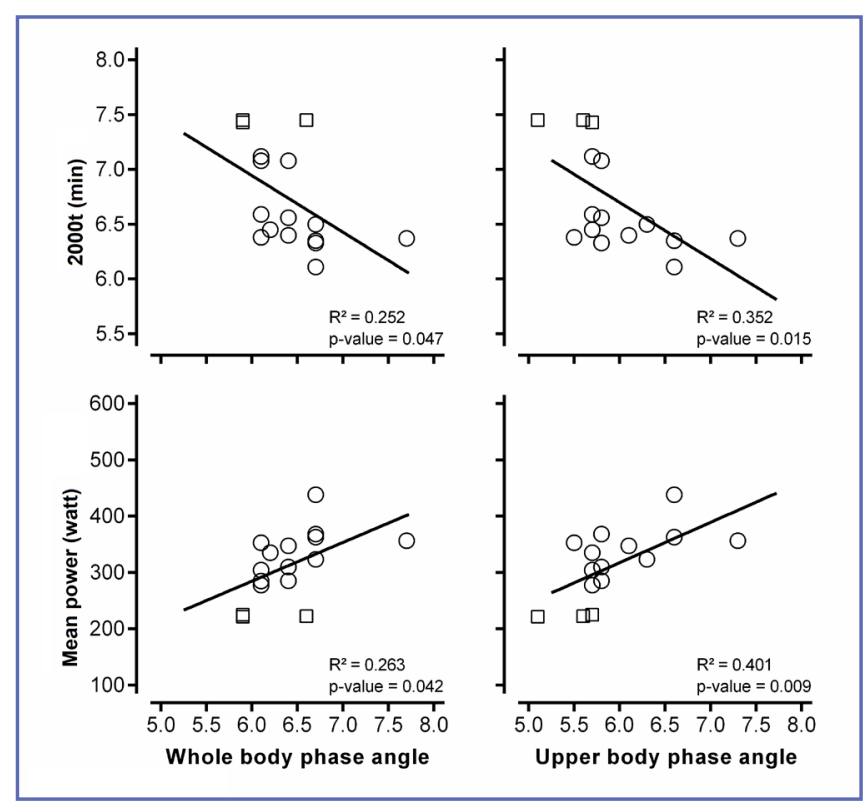

Figure 3. Scatterplots showing the relationships between total and regional phase angle with physical performance measures. The circles represent the male athletes, while the squares represent the female athletes.
Tables III and IV display the multiple regressions between UPhA and 2000t and MP, respectively. These relationships showed a significant trend and not only remained significant after adjusting for the co-variables sex, ALST, and FM\% but the explained variance $\left(\mathrm{R}^{2}\right)$ in the performance predictions increased maintain a variance inflation factor (VIF) below 5 .

\section{DISCUSSION}

Studying the relationship between body composition and sports performance is a growing research area in sports science, especially in the case of elite athletes where the intensity and volume of training are high. The aim of this study was to test the usefulness of regional bioimpedance analysis in evaluations of athletes in which specific body segments such as rowers are involved. Rowing is characterized by the engagement of both the lower and upper limbs; however, the bioelectrical parameters of the upper body appear to be predictive of the performance. As hypothesized, UPhA showed a higher correlation with $2000 \mathrm{t}$ and MP than the WBPhA. To date, this is the first study to investigate the association of regional $\mathrm{PhA}$ with performance parameters, regardless of their important body components such as LST and FM\%.

Table III. Linear regression analysis independent variables and $2000 \mathrm{mt}$ performance.

\begin{tabular}{lllcc}
\hline Independent variable & $\mathbf{R}^{\mathbf{2}}$ & $\boldsymbol{\beta}$ & $\mathbf{9 5 \%}$ confidence interval & P-value \\
\hline UPhA & 0.35 & -0.59 & $-0.91--0.11$ & 0.015 \\
\hline Model 1 & 0.67 & -0.73 & $0.28-1.15$ & $<0.001$ \\
\hline Model 2 & 0.72 & -0.70 & $-0.32-0.77$ & 0.001 \\
\hline Model 3 & 0.72 & -0.63 & $-0.05-0.05$ & 0.005 \\
\hline
\end{tabular}

$\mathrm{R}^{2}$ : coefficient of determination; $\beta$ : Standardized coefficients beta; UPhA: upper hemisoma phase angle; Model 1: adjusted for sex; Model 2: adjusted for sex and arms lean soft tissue; Model 3: adjusted for sex, arms lean soft tissue, and fat mass percentage. 
Table IV. Linear regression analysis independent variables and maximum power.

\begin{tabular}{lllccc}
\hline Independent variable & $\mathbf{R}^{2}$ & $\boldsymbol{\beta}$ & 95\% confidence interval & P-value \\
\hline UPhA & 0.40 & 0.53 & $21.39-121.79$ & 0.009 \\
\hline Model 1 & 0.67 & 0.63 & $-143.61--30.05$ & 0.001 & $<0.001$ \\
\hline Model 2 & 0.77 & 0.69 & $0.56-48.44$ & $-4.41-7.89$ & 0.001 \\
\hline Model 3 & 0.78 & 0.60 & 0 & \\
\hline
\end{tabular}

$\mathrm{R}^{2}$ : coefficient of determination; $\beta$ : Standardized coefficients beta; UPhA: upper hemisoma phase angle; Model 1: adjusted for sex; Model 2: adjusted for sex and arms lean soft tissue; Model 3: adjusted for sex, arms lean soft tissue, and fat mass percentage.

The rowers evaluated in this study showed bioelectric proprieties in line with the references of the athletes' population, falling within the $75^{\text {th }}$ percentile of the tolerance ellipses for males and $50^{\text {th }}$ for females (9). Considering the position of the bioimpedance vectors within the R-Xc graph, the TBW values and the ICW/ECW ratio values measured in the rowers can be compared with those of the athletes' population. In particular, the high pole of the R-Xc graph identifies low TBW values while the vectors positioned at the bottom represent a greater TBW than the average values of the reference population (figure 2). Otherwise, the horizontal axis of the tolerance ellipses identifies a greater or lesser ICW/ECW ratio, where the values increase from the right to the left along the axis. The ICW/ECW ratio is highly correlated with $\mathrm{PhA}$ (16-18), and this it was confirmed by recent studies in athletes where bioelectric measurements were compared with the variables derived from dilution techniques $(17,18)$.

The WBPhA measured in the rowers was $6.5 \pm 0.4$ and 6.1 \pm 0.4 for male and female, respectively. These values were lower than those of the general athletes' population (9), where WBPhA was $7.7 \pm 0.8$ for male and $6.9 \pm 0.8$ for female. On the contrary, the mean WBPhA measured in the rowers tested by Veitia et al. (29) (male: $6.6^{\circ}$; female: $5.8^{\circ}$ ) was similar for the male and lower for the female included in this study. In this regard, previous studies showed that when measuring athletes involved in the same sports a greater WBPhA may be a predictor of a higher competitive category $(8,10,11)$. Considering the regional analysis, the UPhA measured in the male rowers was on average similar with compared to a group of elite athletes practicing different sports evaluated by Marra et al. (30) $\left(6.1^{\circ}\right)$, while the LPhA was lower $\left(9.4^{\circ}\right)$. However, as shown by Silva et al. (31), there is a lack of agreement between the bioimpedance parameters measured with different devices. Therefore, the BIA-data presented in this study may not be comparable with those of Marra et al. (30) where R and Xc were obtained using a multifrequency device. Our athletes were plotted on reference ellipses created starting from measurements made with the same frequency and method of measurement. Furthermore, the equations used to measure body composition variables were also developed with a similar instrument using a foot-to-hand measurement and a frequency of $50 \mathrm{khz}$.

The rowers included in this study performed $2000 \mathrm{mt}$ in a lower time (males in $6.47 \mathrm{~min}$ and females in $7.45 \mathrm{~min}$ ) in comparisons with those involved in the Yoshiga and Higuchi (3) study where the males completed the test in $7.18 \mathrm{~min}$ and females in $8.27 \mathrm{~min}$. In line with our findings, Yoshiga and Higuchi (3) showed that FFM was inversely related with time in performing $2000 \mathrm{~m}$ and this may be justified by the beneficial effects of higher FFM on aerobic performance $(4,5)$. Although our study, at the best of our knowledge, is the first to consider associations between segmental PhA and performance, Nabuco et al. (20) had already investigated the correlations between $\mathrm{PhA}$ and sprint performance in soccer players. In the study by Nabuco et al. (20) the association between WBPhA and physical performance measures lost significance when adjusted for FFM and FM\%. On the contrary, in our study after adjusting for co-variables the variability explained increased up to $72 \%$ and $78 \%$ for $2000 t$ and MP, respectively.

The above-mentioned aspects represent a new and interesting evidence that suggests that in some cases using bioimpedance analysis according to a regional approach may be more informative than the whole-body method. This is certainly an important point of strength of this study in which a sample of elite rowers was included. Furthermore, as showed by the regression analysis results, considering body composition parameters obtained using population-specific equations in addition to $\mathrm{PhA}$ can be highly informative when evaluating athletes.

However, this research is not without limitations. First, the associations between regional $\mathrm{PhA}$ and physical performance parameters were studied according to a pilot study design, therefore including a small sample. Finally, our find- 
ings are not generalizable to all athletes and new research is needed to confirm these findings. Certainly, athletes in which particular body segments are involved, such as the lower hemisome for cyclists, should be included in future studies. In this regard, this study can play a very important role prior exposing Authors in conducting a large-scale research.

\section{CONCLUSIONS}

This pilot study on elite rowers shows how in some sports where particular body segments are predominantly involved, a regional $\mathrm{PhA}$ evaluation may be more informative than the same value assessed using a whole-body approach. In addi-

\section{REFERENCES}

1. Campa F, Matias CN, Marini E, et al. Identifying Athlete Body Fluid Changes During a Competitive Season With Bioelectrical Impedance Vector Analysis. Int J Sports Physiol Perform 2019;11:1-7.

2. Campa F, Semprini G, Júdice PB, Messina G, Toselli S. Anthropometry, Physical and Movement Features, and Repeated-sprint Ability in Soccer Players. Int J Sports Med 2019;40(2):100-109.

3. Yoshiga CC, Higuchi M. Rowing performance of female and male rowers. Scand J Med Sci Sports 2003;13(5):317-21.

4. Mujika I, Rønnestad BR, Martin DT. Effects of Increased Muscle Strength and Muscle Mass on Endurance-Cycling Performance. Int J Sports Physiol Perform 2016;11(3):283-9.

5. Silva AM. Structural and functional body components in athletic health and performance phenotypes. Eur J Clin Nutr 2019;73(2):215-24.

6. Castizo-Olier J, Irurtia A, Jemni M, Carrasco-Marginet M, Fernández-García R, Rodríguez FA. Bioelectrical impedance vector analysis (BIVA) in sport and exercise: Systematic review and future perspectives. PLoS One 2018;7;13(6):e0197957.

7. Kyle UG, Bosaeus I, De Lorenzo AD, Deurenberg P, Elia M, Gómez JM, Heitmann BL, Kent-Smith L, Melchior JC, Pirlich M, Scharfetter H, Schols AM, Pichard C; Composition of the ESPEN Working Group. Bioelectrical impedance analysis--part I: review of principles and methods. Clin Nutr 2004;23(5):1226-43

8. Micheli ML, Pagani L, Marella M, et al. Bioimpedance and impedance vector patterns as predictors of league level in male soccer players. Int J Sports Physiol Perform 2014;9(3):532-9.

9. Campa F, Piras A, Raffi M, Toselli S. Functional Movement Patterns and Body Composition of High-Level Volleyball, Soccer, and Rugby Players. J Sport Rehabil 2019;28(7):740-45.

10. Campa F, Toselli S. Bioimpedance Vector Analysis of Elite, Subelite, and Low-Level Male Volleyball Players. Int J Sports Physiol Perform 2018;13(9):1250-3.

11. Giorgi A, Vicini M, Pollastri L, Lombardi E, Magni E, Andreazzoli A, Orsini M, Bonifazi M, Lukaski H, Gatterer H. Bioimpedance patterns and bioelectrical impedance vector analysis (BIVA) of road cyclists. J Sports Sci 2018;36(22):2608-13. tion to the PhA, the assessment of lean soft tissue mass and FM\% can be highly informative for evaluating performance related parameters.

\section{ACKNOWLEDGEMENTS}

The authors wish to thank the sports club "Canottieri Firenze" for their collaboration by voluntarily making their athletes available.

\section{CONFLICT OF INTERESTS}

The authors declare that they have no conflict of interests.

12. Mascherini G, Gatterer H, Lukaski H, Burtscher M, Galanti G. Changes in hydration, body-cell mass and endurance performance of professional soccer players through a competitive season. J Sports Med Phys Fitness 2015; 55 (78):749-55.

13. Reis JF, Matias CN, Campa F, et al. Bioimpedance Vector Patterns Changes in Response to Swimming Training: An Ecological Approach. Int J Environ Res Public Health 2020;17(13):4851.

14. Nescolarde L, Yanguas J, Lukaski H, Alomar X, Rosell-Ferrer J, Rodas G. Effects of muscle injury severity on localized bioimpedance measurements. Physiol Meas 2015;36(1):27-42.

15. Mulasi U, Kuchnia AJ, Cole AJ, Earthman CP. Bioimpedance at the bedside: current applications, limitations, and opportunities. Nutr Clin Pract 2015;30(2):180-93.

16. Malá L, Zahálka F, Maly T. Bioimpedance for Analysis of Body Composition in Sports. In: Simini F, Bertemes-Filho P. (eds). Bioimpedance in Biomedical Applications and Research. Springer: Cham, 2018: pp. 243-56.

17. Campa F, Matias C, Gatterer H, et al. Classic Bioelectrical Impedance Vector Reference Values for Assessing Body Composition in Male and Female Athletes. Int J Environ Res Public Health 2019;16(24):5066.

18. Marini E, Campa F, Buffa R, et al. Phase angle and bioelectrical impedance vector analysis in the evaluation of body composition in athletes. Clin Nutr 2020;39(2):447-54.

19. Mascherini G, Petri C, Galanti G. Integrated total body composition and localized fat-free mass assessment. Sport Sci Health 2015;11:217-25.

20. Nabuco HCG, Silva AM, Sardinha LB, et al. Phase Angle is Moderately Associated with Short-term Maximal Intensity Efforts in Soccer Players. Int J Sports Med 2019; 40(11):739-43.

21. Organ LW, Bradham GB, Gore DT, Lozier SL. Segmental bioelectrical impedance analysis: theory and application of a new technique. J Appl Physiol (1985) 1994;77(1):98-112.

22. Mascherini G, Castizo-Olier J, Irurtia A, Petri C, Galanti G. Differences between the sexes in athletes' body composition and lower limb bioimpedance values. Muscles Ligaments Tendons J 2018;7(4):573-581. 
23. Marra M, Da Prat B, Montagnese C, et al. Segmental bioimpedance analysis in professional cyclists during a three week stage race. Physiol Meas 2016;37(7):1035-40.

24. Padulo J, Oliva F, Frizziero A, Maffulli N. Muscles, Ligaments and Tendons Journal - Basic principles and recommendations in clinical and field Science Research: 2018 update. Muscles Ligaments Tendons J 2018;8(3):305-7.

25. Lukaski HC, Piccoli A. Bioelectrical Impedance Vector Analysis for Assessment of Hydration in Physiological States and Clinical Conditions. In: Preedy V. (eds). Handbook of Anthropometry. New York, NY: Springer, 2012: pp. 287-305.

26. Matias CN, Campa F, Santos DA, Lukaski H, Sardinha LB, Silva AM. Fat-free Mass Bioelectrical Impedance Analysis Predictive Equation for Athletes using a 4-Compartment Model. Int J Sports Med 2021;42(1):27-32.
27. Sardinha LB, Correia IR, Magalhães JP, Júdice PB, Silva AM, Hetherington-Rauth M. Development and validation of BIA prediction equations of upper and lower limb lean soft tissue in athletes. Eur J Clin Nutr 2020;74(12):1646-52.

28. Secher NH. The physiology of rowing. J Sports Sci 1983;1:23-53.

29. Veitía WC, Deturnell Campo Y, García IE, Aguilera Chavez D, Gutiérrez LRE, Córdova A. Body composition analysis using bioelectrical parameters in the Cuban sporting population. Arch Med Deporte 2017;34(4):207-15

30. Marra M, Di Vincenzo O, Sammarco R, Morlino D, Scalfi L. Bioimpedance phase angle in elite male athletes: a segmental approach. Physiol Meas. 2021;41(12):125007.

31. Silva AM, Matias CN, Nunes CL, et al. Lack of agreement of in vivo raw bioimpedance measurements obtained from two single and multi-frequency bioelectrical impedance devices. Eur J Clin Nutr 2019;73(7):1077-83. 